\title{
Thinking about Thinking Nothing: A Review of Nolen Gertz's Nihilism (MIT P, 2019)
}

"Nihilist" is a very convenient epithet to hurl at someone. Everyone understands that it describes someone who holds objectionable, if not dangerous, views or ways of life. And yet it remains a fuzzy notion: workaday definitions of nihilism differ greatly from-and indeed are surprisingly often diametrically opposed to-what prominent European philosophers have understood it to mean.

Nolen Gertz's Nibilism is an engaging study that sets out to analyze various conceptions and misconceptions of nihilism. Any such enterprise has to survey the intellectual history of what today has come to be known as nihilism, and this Gertz delivers in almost exemplary fashion in the second chapter. In his history of nihilism from Socrates to Friedrich Nietzsche via René Descartes, David Hume and Immanuel Kant, the author manages to summarize key tenets of these most influential thinkers while dexterously driving forward his discussion of nihilism, thereby demonstrating that Western philosophy developed alongside, and frequently in reaction to, the epistemological and existential threat of nihilism, which so often lurks ominously around those who dare to explore the shadowy byways of scepticism. It might have been expedient to mention Gorgias of Leontinoi, as well (whose moniker, "Gorgias the Nihilist," though hotly disputed, nevertheless attests to his relevance to this subject), or to speak more about the idea of solipsism (mentioned only in passing on p. 27), but that might be asking too much of an informative but slim book that makes no claim to exhaustion of the topic at hand.

This admirable synthesis of Western thought from the point of view of the conceptual development of nihilism is then followed by an equally accomplished chapter which establishes helpful parallels-and, perhaps more importantly, vital differences-between nihilism and kindred concepts 
such as pessimism, cynicism and apathy. In what must come as a surprise to some readers, the author establishes that someone can in fact be optimistic, idealistic, sympathetic, and pursue happiness and still be a nihilist; this is partly because for Gertz, as for most of the philosophers studied in Nibilism, "nihilism is about evading reality rather than confronting it" (73). A pessimist is too self-aware to do so, whereas optimism breeds a happy complacency that fits that conception of nihilism like a glove. Likewise, the cynic's distrustful brand of realism makes them less vulnerable to nihilism than the idealist's forward-looking and less grounded worldview. Finally, while apathy entails a partial or complete emotional detachment, the strong feelings stirred by sympathy are more compatible with the absorbing, reality-alienating nature of nihilism.

In the fourth chapter, the author goes on to examine four ways of thinking of nihilism: as denial (along Nietzschean lines); as denial of death (from an existentialist perspective); as denial of the death of meaning (or the postmodern debasement of metanarratives); and as denial of the death of meaning of childhood (that is, the anxiety of freedom and the nihilistic nostalgia for a child-like lack of responsibility, as identified by Simone de Beauvoir). Gertz deserves credit for laying out these intriguing ideas, as well as the rest of the book, in an emphatically accessible way, as attested by the book's playful cover illustration and the author's constant allusions to popular culture and well-known apps (and by the ubiquity of the phrase "in other words," which occurs 45 times).

While the effort to appeal to an audience that might be less familiar with the intricacies of Western philosophy is certainly laudable, this approach is not without its risks. The countless examples drawn from modern popular culture are not always illuminating, sometimes coming across as superfluous or even confusing (it is understandable that Holden Caulfield's self-righteous, anti-nihilistic zeal should itself be perceived as nihilistic, but how can that logic possibly apply to a character like Lisa Simpson?). Moreover, while certain rhetorical flourishes such as the use of dramatic tricolons also seem intended to improve the reading experience, they can be slightly distracting when resorted to as frequently as they are. Yet such shortcomings should not detract from the important benefits that this more colloquial approach provides, including the way it may lend clarity and contemporary relevance to the discussion of an arguably rather daunting subject for a non-specialist audience.

The fifth chapter is perhaps the least convincing. It deals with the cultural framework of nihilism: nihilism, the author shows, is found not only in time-worn books penned by Continental philosophers but everywhere today (on TV, in the classroom, in the workplace and in politics), equally decried in rhetoric and championed in practice. While the arguments for 
the disturbing presence of nihilism in the two last domains are cogent, the claims related to the first two are rather less so, especially the subchapter about education: the use of screens in pedagogical contexts is simplistically linked to the pressures of content glut that are fed by phenomena such as binge-watching; the nefariousness of plagiarism is reduced to a moral issue (as opposed, for instance, to being deemed inimical to critical thinking, which incidentally is one of the least nihilistic faculties conceivable); and in general what is attacked is an outdated view of learning, which, while certainly still prevalent in certain contexts, has long ago been superseded in education studies. Some of these sweeping claims ought to have been adjusted and refined through a stronger engagement with the voluminous recent scholarship on related topics in pedagogy.

The last chapter is once again on a more solid footing. It delves into the relationship between technology and nihilism (explored by Gertz at greater length in a book that was published one year before this one) and it yields interesting insights, such as the conservative nature of technological progress as far as values are concerned. The Nietzschean idea of fighting passive nihilism with active nihilism is also thought-provoking, and it would have been fruitful to dwell on it a while longer (as the author does in a noteworthy article he wrote this year for Aeon magazine). Complete with a brief glossary of helpful terms to navigate the murky waters of nihilism and some unobtrusive endnotes that are exclusively related to bibliographical references, Gertz's Nibilism is a great starting point for the exploration of nihilism in its many guises.

\section{Pedro Querido is a PhD candidate in Comparative Studies} at the School of Arts and Humanities, University of Lisbon. His current research focuses on the theme of old age in mid-twentieth-century radio art, and his research interests include twentieth-century fiction and drama, comparative literature and irrationality in literature.

https://orcid.org/0000-0002-8865-277X

pedro_sq@hotmail.com 